\title{
Model Pembelajaran RADEC dalam Perspektif Filsafat Konstruktivisme Vygotsky
}

\author{
Aditya Rini kusumaningpuri ${ }^{1 \circledast}$ \& Endang Fauziati ${ }^{2}$
}

Universitas Muhammadiyah Surakarta, Indonesia

${ }^{\bowtie}$ E-mail: adityakusumaningpuri36@guru.sd.belajar.id

\begin{abstract}
Abstrak
Tujuan penelitian ini untuk mendeskripsikan model pembelajaran RADEC (Read, Answer, Disscuss, Explain, and Create) dalam perspektif filsafat konstruktivisme Vigotsky. Penelitian ini menggunakan library research atau penelitian kepustakaan berdasarkan data-data kepustakaan, yaitu mengkaji model belajar RADEC dan filsafat konstruktivisme vigotsky yang dilakukan dengan menggunakan literatur berupa aturan yang mendukung dalam menganalisis topik penelitian. Adapun pendekatan yang digunakan dalam penelitian adalah pendekatan kualitatif dengan metode deskriptif. Dalam penelitian ini, peneliti mencoba mengeksplorasi dan memberikan argumen yang berkaitan dengan model pembelajaran RADEC dengan analisis filsafat konstruktivisme vigotsky. Hasil penelitian menunjukan bahwa model pembelajaran RADEC melalui sintak-sintaknya sesuai dengan teori konstruktivime Vigotsky dimana kemampuan aktual siswa terlihat ketika menyelesaikan tugas tanpa bantuan oarang lain dan kemampuan potensial siswa terlihat ketika menyelesaikan tugas dengan bantuan oarang lain. Sedangkan ZPD merupakan daerah antara kemampuan aktual dan kemampuan potensial. Selama proses pembelajaran dengan model RADEC terjadi pemagangan kognitif (cognitive apprenticeship) yaitu proses dimana seseorang belajar tahap demi tahap dari mulai read $(R)$ sampai create $(C)$ untuk memperoleh pengetahuan melalui interaksi dengan ahlinya.
\end{abstract}

Kata Kunci: RADEC; Konstruktivisme Vygotsky; ZPD.

\begin{abstract}
This research aims to understand, uncover and try to understand the learning model of RADEC (Read, Answer, Disscuss, Explain, and Create) in the perspective of vigotsky constructivism philosophy. This is because Vigotsky's school of constructivism philosophy requires learners to use their abilities to adjust to the demands of scientific development and their time. The activeness of learners is very decisive in developing knowledge, not just receiving feeds and ready-to-eat knowledge from teachers or other learners. This type of research is literature research, which has been arranged according to the literature so that it can be used to analyze the results of research. So this study uses qualitative approaches and descriptive methods. This study wanted to provide an input and implementing related to the radec learning model with the analysis of vigotsky constructivism philosophy. The results showed that radec learning model through its syntax in accordance with vigotsky constructivism theory where this theory of learning is a theory of learning that a student when learning needs a help from another party, because there is a limitation zone in him called as Proximal Development Zone $(Z P D)$ or Proximal Development Zone, meaning a need a second party to help in solving a problem that is happening.
\end{abstract}

Keywords: RADEC; Vygotsky Contsructivism; ZPD. 


\section{PENDAHULUAN}

Berbagai model pembelajaran inovatif diciptakan dalam rangka membantu siswa memiliki keterampilan abad 21 (komunikasi, berfikir kritis dan memecahkan permasalahan, kolaborasi, serta berfikir kreatif), sering disebut dengan istilah $4 \mathrm{C}$ meliputi Communication, Critical thinking and Problem solving, Collaboration, dan Creative Thinking. Untuk itu perubahan proses pembelajaran mutlak dilakukan sesuai perkembangan jaman. Bahkan John Dewey menyatakan seandainya seorang guru cara mengajarnya sama dengan cara-cara ia mengajar kemarin diibaratkan bahwa ia sedang merampok masa depan siswanya. Untuk itulah proses pembelajaran harus terus berubah disesuaikan dengan tuntutan jaman.

Kurikulum yang ada di Indonesia sudah memuat keterampilan 4C bahkan lebih lengkap karena menyangkut aspek spiritual dan karakter sosial. Agar tujuan kurikulm tercapai maka berbagai model pembelajaran inovatif sangat di sarankan agar bisa diterapkan saat proses belajar mengajar. Pendidikan di indonesia telah menerapkan model inovatif yang seperti dengan menerapkan model pembelajaran RADEC (Read, Answer, Disscuss, Explain, and Create) dari hasil penerapan Sopandi. Sehingga Model pembelajaran RADEC yang pertama kali menggunakan yaitu Sopandi ketika acara konferensi internasional di Kuala Lumpur, Malaysia. (Pohan et al., 2019) Sehingga dengan model itu tentunya diharapkan dapat memberikan suatu peningkatan pada kualitas pembelajaran dan mampu memberikan motivasi kepada siswa agar mampu menguasai kompetensi dan juga keterampilan abad 21. Model pembelajaran RADEC yaitu suatu model pembelajaran yang sering digunakan di Indonesia.

(Wahyu Sopandi \& PPPPTKIPA, n.d.)
Nama model pembelajaran RADEC (Read, Answer, Disscuss, Explain, and Create) agar mudah diingat urutan implementasiya maka disesuaikan dengan sintaks pembelajarannya. Nama model pembelajaran seringkali tidak menggambarkan sintaks pembelajarannya. Bahkan ada model pembelajaran yang sama sintaks nya dapat beragam.

Keunggulan model pembelajaran RADEC, diantaranya yaitu (1) Guru mampu mendesain model yang digunakan agar proses pembelajaran menjadi menarik, (2) Dapat meningkatkan kinerja berpikir kritis peserta didik, (3) Kemampuan menganalisa dan membaca peserta didik meningkat, (4) Meningkatkan kerjasama kelompok (Kaharuddin,2020), (5) Keunggulan model RADEC ada pada sintaks yang mudah tangkap oleh pemahaman seorang pendidik. Sesuai dengan hasil risetnya Handayani dan Sopandi pada tahun 2019 menyatakan bahwa sekitar 97,2 \% pendidik yang sudah mengikuti pelatihan sampai selesai mempunyai ketertarikan untuk menggunakan model RADEC di sekolah seban model pembelajaran itu mudah untuk dipahami dan juga mampu memberikan dorongan dalam membangun karakter siswa dan mampu memberikan suatu pemahaman konseptual siswa serta memberikan suatu motivasi dalam mengembangkan kompetensi abad 21 bagi siswa (Sopandi, 2019).

Siswa dituntut aktif ketika proses pembelajaran tatkala menggunakan model RADEC. Karena pembelajaran akan lebih bermakna bila siswa terlibat secara aktif pada kegiatan belajar mngajar. Sehingga hal itu sesuai dengan risetnya (Pratama, et.al 2020) menyatakan bahwa model pembelajaran RADEC dapat memberikan pengaruh yang positif pada keterampilan berfikir tingkat tinggi, dari pada dengan menggunakan model 
pembelajaran inkuiri terhadap keterampilan berfikir tingkat tinggi siswa.

Penjelasan di atas dapat dibuktikan dari risetnya Pohan et al.,(2019) melakukan penelitian yang berjudul "Model Pembelajaran RADEC dalam Pembelajaran Membaca Pemahaman Siswa". Dari penelitian ini menunjukkan bahwa pembelajaran memakai model RADEC melalui sintaknya (Read-Answer-DiscussExplain-Create) sudah mencakup aspek kompetensi abad 21 ialah siswa mampu berpikir kritis dan memecahkan masalah, mempunyai kreatif dan juga komunikatif serta kolaboratif. Model pembelajaran RADEC juga dapat dijadikan solusi bagi permasalahan peserta didik terhadap rendahnya tingkat literasi membaca. Model pembelajaran ini juga memberikan pengaruh terhadap hasil pembelajaran peserta didik Sekolah Dasar, khususnya pada bidang pengetahuan. Sehingga sesuai dengan risetnya Andini \& Fitria ( 2021).

Berkenaan dengan paparan di atas, perkembangan ilmu pengetahuan yang begitu pesat pada beberapa dekade ini, menimbulkan dampak masyarakat global termasuk pada aspek pendidikan terutama dalam pembelajaran. Sebab sebagaimana kita tahu proses belajar mengajar sangat erat kaitannya dengan bagaimana proses anak dalam belajar. Bertititk pada persoalan perlu adanya perubahan dalam menyikapi perkembangan ilmu pengetahuan perlu sebuah alternatif agar pembelajaran menjadi efektif. Teori konstruktivisme diharapkan dapat menjadi salah satu alternatif yang menjawab keadaan tersebut.

Sehingga Model Pembelajaran RADEC itu untuk memahami, menguak dan mencoba memahami model pembelajaran tersebut dalam persepektif aliran filsafat konstruktivisme Vigotsky menarik untuk dikaji. Hal ini dikarenakan, Aliran filsafat konstruktivisme Vigotsky menghendaki agar peserta didik menggunakan kemampuan yang dimilikinya untuk menyesuaikan diri dengan tuntutan perkembangan keilmuan dan zamannya.

Keaktifan peserta didik sangat menentukan dalam mengembangkan pengetahuan, bukan hanya menerima umpan dan pengetahuan siap saji dari guru atau peserta didik lain. Sehingga diharapkan siswa mampu mentransformasikan infomasi yang komplek ke situasi yang lain. Maka ilmu pengetahuan dapat dikembangkan oleh siswa jadi tidak hanya menerima pengetahuan saja.

\section{METODE PENELITIAN}

Jenis penelitian ini termasuk penelitian kepustakaan atau library research, dengan memakai literatur untuk memudahkan dalam menganalisis hasil penelitian. Penelitian kepustakaan adalah suatu pendekatan yang menggunakan bahan referensi kepustakaan untuk mengumpulkan informasi dan data penelitian sebagai bahan penelitian. Objek penelitian berupa data kepustakaan. Data perpustakaan yang dimaksud antara lain buku teks, disertasi, disertasi, jurnal penelitian, laporan penelitian, laporan seminar, tesis, dokumen hasil diskusi ilmiah, dan dokumen resmi pemerintah (Sugiyono, 2014).

Metode yang dipakai dalam penelitian ini yaitu metode kualitatif. Metode deskriptif kualitatif untuk mendeskripsikan suatu fenomena yang berhubungan dengan kebutuhan pendidikan untuk menghadapi abad 21. Sehingga peneliti melakukan eksplorasi dan juga memberikan argumen terkait model pembelajaran RADEC dengan analisis filsafat konstruktivisme vigotsky.

\section{HASIL DAN PEMBAHASAN}

Hasil dan pembahasan pada artikel ini 
memuat hasil temuan dan analisis terhadap studi kepustakaan yang telah dilakukan. Pembahasan meliputi (1) Filsafat konstruktivisme, (2) Konstruktivisme Lev Vigotsky, (3) RADEC dalam perspektif konstruktivisme Vygotsky. Ketiga pokok bahasan ini dijelaskan sebagai berikut.

\section{Filsafat Konstruktivisme}

Definis konstruktivisme yaitu suatu aliran ilmu pengetahuan dan teori belajar yang memberikan penekanan pada ilmu pengetahuan secara konstruksi. Namun bisa dikatakan bahwa konstrukstivisme tidak bisa diketahui siapa dan kapan yang melakukan teori konstruktivisme di masa modern (Ahmad Abrar Rangkuti., 2015.).

Konteks pendidikan atau belajar mengajar, konstruktivisme terwujud secara formal yang digunakan sebagai teori pengetahuan dan teori belajar sejak tahun 1980-1990-an melalui karya Bruner dan Von Glaseerfeld digunakan dikalangan pendidik. Dalam beberapa litelatur terkait dikatakan bahwa Von Glaseerfeld merupakan salah seorang pionir gerakan konstruktivis (Glaseerfeld, 1997 dalam Dadang Supardan (2016).

Konstruktivisme merupakan cabang dari teori kognitivisme. Bila ditelusur kebelakang teori kognitivisme mempunyai dasar atas teori Jean Piaget dan Lev Vygotsky. Dalam perkembangannya Jean Piaget disebut Piaget Consturctivism sedangkan Vygotsky dikenal sebagai Vigotsky Contructivism Social.

Pada segi konstruktivistik menyatakan bahwa suatu lingkungan belajar dapat membantu dalam mewujudkan beberapa pandangan dan juga interpretasi pada realitas, konstruksi pengetahuan, serta kegiatan yang lain dengan dasar pengalaman. Sehingga mewujudkan ide untuk melakukan evaluasi belajar konstruktivistik.
Adanya Teori belajar konstruktivistik yang digunakan dapat memberikan transformasi ilmu pengetahuan dalam konstek pengalaman dan juga pengetahuan terhadap siswa yang mengikuti proses belajar. Sehingga guru bisa memberikan suatu bantuan kepada siswa dalam memberikan pemahaman representasi fungsi konseptual dunia eksternal. (M. Nugroho Adi Saputro, 2021).

\section{Konstruktivisme Lev Vigotsky}

Teori konstruktivisme menekankan pembahasan psikologi perkembangan pada sudut pandang sociocultural. Atas ketertarikannya pada bahasa, Vigotsky akhirnya dapat memahami proses berfikir karena bahasa berhubungan erat dengan proses berfikir manusia. Sehingga berbahasa dapat terwujud menjadi ketrampilan dengan dukungan kemampuan kognisi. Atas dasar tersebut berkembang menjadi pandangan Vigotsky mengenai bahasa dalam konteks sosiokultural psikologi perkembangan.

Teori konstruktivisme, Vigotsky merupakan peletak dasar konstruktivisme sosial yang tidak memisahkan individu dari latar belakang dan peran sosialnya. Pemikiran Vigotsky ini berbeda dengan konstruktivisme kognisi Piaget yang menekankan proses belajar berorientasi pada individu. (M. Nugroho Adi Saputro, 2021). Teori belajar yaitu suatu proses belajar yang mana seorang siswa membutuhkan bantuan gurun untuk menyelesaikan masalah yaitu termasuk dalam zona keterbatasan dirinya atau Zona Proksimal Development (ZPD) maupun Zona Perkembangan Proksimal.

Teori konstruktivisme Vigotsky dikatakan sebagai teori konstruksi sosial yang memberikan penekanan bahwa intelegensi manusia berasal dari masyarakat, lingkungan dan budayanya. Seorang individu mempunyai kognitif sejak melakukan 
interpersonal (interaksi dengan lingkungan sosial). Vygotsky menyatakan bahwa dengan alat berfikir dapat memberikan pengaruh dalam mengembangkan kognitif pada diri seseorang.

Teori belajar dapat memberikan suatu perubahan dari segi kognitif. Teori belajar dibagi menjadi 3 konsep utama, antara lain 1) Hukum genetik mengenai perkembangan, 2) Zona perkembangan proksimal dan 3) mediasi.

\section{Pertama, Hukum genetik}

perkembangan. Menurut Vigotsky hukum genetik mengenai perkembangan keterampilan, akan tetapi melewati dua dimensi yaitu dimensi sosial dan dimensi psikologis. Dimensi sosial dapat dilihat dari lingkungan seseorang dan dimensi psikologis dilihat dari dalam diri seseorang. Teori ini memandang lingkungan sosial sebagai komponen utama pembentukan pengetahuan dan perkembangan kognitif. Oleh karena itu, belajar dan perkembangan merupakan penentu perkembangan kognitif seseorang. Vygotsky percaya bahwa kedewasaan adalah prasyarat untuk berpikir sempurna, tapi ia tidak percaya bahwa kedewasaan secara keseluruhan akan menentukan jatuh tempo berikutnya.

\section{Kedua, Zona Perkembangan}

Proksimal, Zona Perkembangan Proksimal atau Zona Proximal Development (ZPD) yaitu suatu konsep dasar dalam pembelajaran ko-konstruktivistik Vygotsky. Zona Perkembangan Proksimal mempunyau makna yang dijelaskan oleh Vygotsky sebagai perbedaan antara tingkat perkembangan aktual ditentukan oleh pemecahan masalah individu dan tingkat perkembangan ditentukan oleh pemecahan masalah di bawah bimbingan orang dewasa atau bekerja sama dengan rekan-rekan lebih mampu. Vygotsky mengemukakan bahwa
ZPD memiliki empat tahap dalam pengembangan dan pembelajaran (Schunk, 1986), yaitu: Tahap (1) Perilaku anak masih dipengaruhi atau dibantu oleh orang lain, Tahap (2) Tindakan anak didasarkan pada inisiatifnya sendiri, Tahap (3) Perilaku anak berkembang dan terinternalisasi secara spontan, Tahap (4) Tindakan spontan anak akan diulang sampai anak siap untuk berpikir abstrak.

Sehingga dari hal itu, disimpulkan bahwa seorang yang meminta bantuan kepada orang yang lebih pengalaman itu maka lebih berkompeten.

Ketiga, Mediasi, Mediasi adalah tanda atau simbol bahwa penggunaan orang untuk memahami hal-hal di luar pemahamannya. Ada dua jenis mediasi yang dapat mempengaruhi belajar, yaitu (1) Tema mediasi semiotik, di mana simbol-simbol atau tanda-tanda yang dipakai oleh seseorang untuk memahami hal-hal di luar pemahaman mereka diperoleh dari hal-hal yang tidak di sekitar kita, maka orang yang memahami bantuan yang lebih baik, membangun pemikiran kita, dan akhirnya kita memahami maknanya; (2) Perancah adalah tanda atau simbol yang digunakan oleh orang-orang untuk memahami hal-hal di luar pemahaman mereka diperoleh dari hal-hal yang sudah ada di lingkungan mereka, maka orang yang sudah mengerti tanda atau simbol akan membantu menjelaskan kepada orang-orang yang tidak mengerti, sehingga mereka mengerti apa artinya. Menurut teori Vygotsky, berbagai hal perlu diperhatikan dalam proses pembelajaran antara lain: Berdasarkan teori Vygotsky dapat disimpulkan beberapa hal yang perlu untuk diperhatikan dalam proses pembelajaran, yaitu: (a) Siswa lebih leluasa dalam mendapatkan ilmu pengetahuan dari zona perkembangan proksimalnya atau potensinya 
melalui belajar dan berkembang. (b) Tingkat perkembangan potensial lebih berhubungan dalam pembelajaran daripada perkembangan aktualnya, (c) Penggunaan strategi dalam pembelajaran lebih diarahkan agar mampu mengembangkan kemampuan intermentalnya dibandingkan kemampuan intramentalnya, (d) Kesempatan diberikan kepada siswa seluas luasnya agar dapat mengintegrasikan pengetahuan deklaratif yang didapatkan untuk memecahkan masalah, dan (e) Proses belajar mengajar lebih merupakan ko- konstruksi, tidak sekedar transferal.

\section{RADEC Dalam Perspektif Konstruktivisme Vygotsky}

Sintaks pembelajaran RADEC (Read, Answer, Disscuss, Explain, and Create) mengacu pada filsafat konstruktivisme Vygotsky dalam empat tahap perkembangan ZPD yang sejalan dengan proses belajar yang membentuk proses mengkonstruksi pengetahuan, bukan proses menerima pengetahuan.

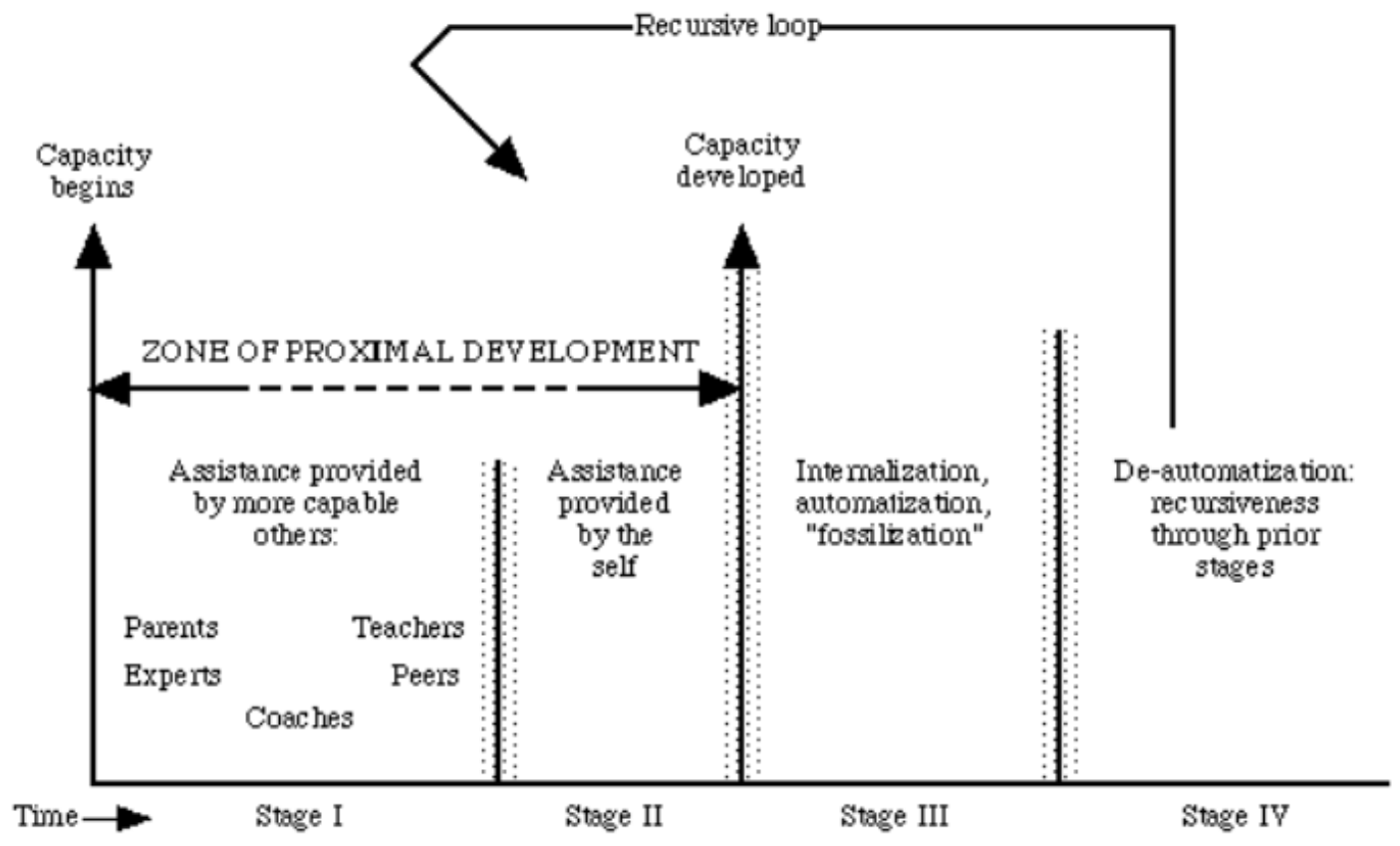

Gambar 1. Empat tahap perkembangan ZPD (Tharp \& Gallimore, 1988:35) dikutip dari Yohanes (2010)

\section{Tahap Read (R) atau Membaca}

Pada taraf ini siswa mencari data dari berbagai sumber, antara lain buku, sumber data tercetak, dan sumber informasi lainnya, misalnya lewat internet. Untuk membimbing siswa mencari informasi, pertanyaan pra pembelajaran diberikan kepada siswa berdasarkan materi yang telah mereka pelajari. Tingkat berpikir yang dibutuhkan oleh pertanyaan harus berkisar dari Lower Order Thinking (LOT) hingga Higher order thinking (HOT). Mulai dari mengingat informasi, mengembangkan contoh soal produktif, rumusan masalah, dan rencana produk yang dapat dikembangkan berdasarkan materi yang dipelajari.

Pertanyaan pra-sekolah diajukan sebelum pembelajaran di kelas. Untuk menjawab pertanyaan tersebut, kegiatan menggali informasi dilakukan sendiri oleh siswa di luar kelas. Kegiatan ini didasarkan pada gagasan bahwa informasi dapat diperoleh tanpa bantuan orang lain. Siswa dapat meminta teman-teman (peer tutor) atau guru selama pertemuan kelas. Dengan metode ini, pendidikan di kelas dapat mengembangkan pengembangan aspek-aspek lain yang memerlukan interaksi dengan orang lain dalam perkembangannya. Dengan membagikan tugas mandiri sebelum 
pembelajaran dikelas akan mendorong pembelajaran dikelas lebih fokus pada materi yang dianggap sulit.

Pada sintaks Read (membaca) inilah tindakan anak masih dipengaruhi orang lain terutama orang tua. Tahap pertama pada ZPD ini disebut More Dependence to Others Stage. Hal ini seorang siswa selalu mendapatkan bantuan dari pihak lain dalam memecahkan masalah. Sehingga terwujudnya model pembelajaran kooperatif maupun kolaboratif dalam mengembangkan kognitif pada anak secara konstruktif.

\section{Tahap Answer (A) atau Menjawab}

Pada tahap ini siswa menjawab pertanyaan pra-learning berbasis pada pengetahuan yang diperoleh pada tahap membaca (R) dalam bentuk Kegiatan Mahasiswa Lembar (LKS). Dengan kegiatan ini, siswa secara mandiri melihat kesulitan materi dengan mengidentifikasi kesulitan dalam menjawab pertanyaan pra-belajar. Prelearning pertanyaan yang diberikan oleh guru kepada siswa dapat mendorong siswa untuk memperoleh pemahaman dari informasi yang mereka baca.

Tahap answer ini, siswa menanggapi persoalan pra-pembelajaran bersumber pada pengetahuan yang diperoleh pada tahap membaca (R) pada Lembar aktivitas Siswa atau LKS. Pada kegiatan ini, siswa secara mandiri memandang kesukaran, mengenali perihal apa saja yang jadi kesukaran dalam menanggapi pertanyaan pra pembelajaran.

Sedangkan di tahap answer (A) yang mana kinerja siswa tidak banyak mengharap dari pihak lain. Siswa lebih fokus pada self assistance, sehingga siswa dapat membantu dirinya sendiri.

\section{Tahap Discuss (D) atau Berdiskusi}

Selama diskusi ini, siswa belajar dengan menjawab pertanyaan dari pertanyaan pra-studi. Dalam kegiatan ini guru mendorong siswa untuk aktif dalam berdiskusi. Guru juga memotivasi siswa yang telah menyelesaikan tugas dan menjawab dengan baik. Siswa yang belum berhasil dalam menggunakannya, guru memberikan kesempatan untuk meminta siswa yang telah menguasai materi. Dengan cara ini guru dapat mengetahui kelompok atau yang memiliki ide-ide kreatif sebagai bentuk menerapkan konsep dikuasai. Jadi sintaks ini masih termasuk dalam tahap self-bantuan pada tahap ZPD karena anak-anak dapat membantu diri mereka sendiri dengan meminta rekan-rekan mereka atau guru.

Guru bisa menganalisa tugas dari semua siswa atau kelompok mengalami kesulitan. Dimana kesulitan ini kemudian dipaparkan oleh guru klasik untuk semua kelompok pada tahap menjelaskan (E). Diskusi tahap (D) berakhir ketika siswa telah menyelesaikan tugas diskusi mereka atau tidak dapat melanjutkan pekerjaan mereka karena kesulitan.

\section{Tahap Explain (E) atau Menjelaskan}

Tahap kegiatan ini adalah presentasi klasik. Materi yang disajikan meliputi semua aspek kognitif indikator pembelajaran yang terkandung dalam belajar. Urutan presentasi disesuaikan dengan urutan indikator disusun dalam rencana pelajaran. Pada tahap ini, perwakilan mahasiswa diminta untuk menjelaskan konsep-konsep dasar mereka telah menguasai di depan kelas. Dalam kegiatan ini, memastikan guru bahwa materi dijelaskan secara ilmiah dan bahwa semua siswa memahami penjelasan.

Sintaks Jelaskan (E) atau tahap menjelaskan di mana kinerja anak lebih terinternalisasi secara otomatis. Tahap ketiga dalam ZPD disebut Internalisasi dan Otomasi Stage. Pada tahap ini, kesadaran akan pentingnya pengembangan diri dapat muncul dengan sendirinya tanpa paksaan atau arahan 
dari pihak lain. Tapi anak-anak pada tahap ini belum mencapai kematangan benar karena mereka masih menemukan diri mereka sendiri.

\section{Tahap Create (C) atau Mengkreasi}

Pada tahap mencipta, guru mendorong dan menginspirasi untuk menggunakan pengetahuan yang telah dimilikinya untuk memecahkan masalah dimana hasil akhir dari pemecahan masalah tersebut dapat berupa produk.

Guru dapat menginspirasi siswa untuk memunculkan ide - ide kreatif dengan memberikan model desain kreatif yang belum pernah diwujudkan sendiri atau orang lain. Pada tahap ini siswa, mengkomunikasikan ide - ide kreatif, membuat keputusan tentang ide - ide yang akan diwujudkan, merencanakan, melaksanakan, melaporkan dan mempresentasikan hasil ide kreatif dalam berbagai bentuk.

Secara sintaksis, create (C) atau explain merupakan tahap dimana penampilan anak mengungkapkan perasaan dari hati, jiwa dan emosi yang dilakukan secara berulangulang. Tahap keempat dalam ZPD disebut Tahap De-otomatisasi. Pada tahap ini, apa yang disebut otomatisasi de exit yang merupakan puncak kinerja yang sebenarnya.

\section{KESIMPULAN}

Teori belajar Vigotsky adalah salah satu teori pembelajaran sosial, sehingga sangat cocok digunakan untuk model pembelajaran RADEC (Baca, Jawaban, Diskusi, Jelaskan, dan Buat) karena dalam model pembelajaran RADEC ada interaksi sosial, yaitu interaksi antara sesama mahasiswa dan sesama mahasiswa. siswa dan guru, untuk menemukan pemecahan masalah konsep. Selama proses interaksi, magang kognitif terjadi, yang merupakan proses di mana seseorang belajar secara bertahap dari membaca (R) untuk menciptakan (C) untuk pengetahuan memperoleh melalui interaksi dengan para ahli.

Teori konstruktivisme Vygotsky menjelaskan bahwa belajar terjadi ketika anak-anak belajar untuk melakukan tugastugas yang belum dipelajari namun tugas tersebut masih dalam kisaran kemampuan atau tugas yang di Zona Pengembangan proksimal (ZPD).

Memahami dan menerapkan cara pandang aliran filsafat konstruktivisme Vigotsky yang di integrasikan dalam model pembelajaran RADEC, diharapkan dapat dijadikan solusi bagi permasalahan peserta didik terhadap rendahnya tingkat literasi membaca. Sehingga pendidikan di Indonesia semakin berkualitas, dan sesuai dengan harapan rakyat Indonesia.

\section{DAFTAR RUJUKAN}

Andini, S. R., \& Fitria, Y. (2021). Pengaruh Model RADEC pada Pembelajaran Tematik terhadap Hasil Belajar Peserta Didik Sekolah Dasar. JURNAL BASICEDU. 5(3), 1435-1443.

Hayati, F. (2021). Karakteristik Perkembangan Siswa Sekolah Dasar: Sebuah Kajian Literatur. 5, 1809-1815.

Kholifah, U. (2020). PENGEMBANGAN BUKU SAKU BERBANTUAN GAMBAR BERSERI UNTUK MENINGKATKAN KETERAMPILANMENULIS TEKS EKSPLANASI BAHASA INDONESIA KELAS V SDN SAMPANGAN 01 SEMARANG (Doctoral dissertation, Universitas Negeri Semarang).

Mangun Wardoyo Sigit, Pembelajaran Konstrutivisme Teori dan Aplikas Pembelajaran dalam Pembentukan Karakter, Bandung: Alfabeta, 2013.

Mai, F. R. (2019). Analisis Kemampuan dalam Menentukan Ide Pokok pada Teks Eksplanasi Siswa Kelas V SD SeGugus 4 Kecamatan Klojen Kota Malang. SKRIPSI Jurusan 
Kependidikan Sekolah Dasar \& Prasekolah-Fakultas Ilmu Pendidikan UM.

Martini, S. (2019). Landasan Filsafat Konstruktivisme Dalam Pembelajaran Sains. Jurnal Biologi and Pendidikan Biologi, 3(2), 88-99.

M. Nugroho Adi Saputro, P. L. P. (2021). MENGUKUR KEEFEKTIFAN TEORI KONSTRUKTIVISME DALAM PEMBELAJARAN. 4, 16.

Muhibin, M., \& Hidayatullah, M. A. (2020). Implemntasi Teori Belajar Konstruktivisme Vygotsky Pada Mata Pelajaran Pai Di SMA Sains Qur`An Yogyakata. Belajea; Jurnal Pendidikan Islam, 5(1), 113. https://doi.org/10.29240/belajea.v5i1.1 423

Payong, M. R. (2020). Zona Perkembangan Proksimal dan Pendidikan Berbasis Konstruktivisme Sosial Menurut Lev Semyonovich Vygotsky. Jurnal Pendidikan Dan Kebudayaan Missio, 12(2), 164-178.

Pohan, A. A., Abidin, Y., Sastromiharjo, A., \& Indonesia, U. P. (2019). MODEL PEMBELAJARAN RADEC. 496.

Pratama, et. a. - Jin. (Jurnal I. P. 6(2) (2020). (2015). Pengaruh model pembelajaran RADEC terhadap keterampilan berpikir tingkat tinggi siswa sekolah dasar Jurnal Inovasi Pembelajaran (JINoP). JINoP (Jurnal Inovasi Pembelajaran), 1(1), 191-203. https://doi.org/10.22219/jinop.v1i1.244 1

Rangkuti, A. A. (n.d.). Teori pembelajaran konstruktivisme. 1-15.

Rimayanti, A. I., \& Jaja, J. (2018). PENGEMBANGAN BAHAN AJAR TEKS EKSPLANASI BERDASARKAN BERITA MEDIA MASSA

Tuturan, 7(2), 857-862.

Rizky Wahyuning Esa, Penerapan Teori Belajar Konstruktivisme Pada Pembelajaran Pendidikan Agama Islam Berbantuan Media Video Kelas VII Di SMPN 87 Jakarta, Jurusan Pendidikan
Agama Islam Fakultas Ilmu Tarbiyah Dan Keguruan Universitas Islam Negeri Syarif Hidayatullah Jakarta 2017. PDF

Setiawan, D., Sopandi, W., \& Hartati, T. (2019). Kemampuan menulis teks eksplanasi dan penguasaan konsep siswa sekolah dasar melalui implementasi model pembelajaran RADEC. Premiere Educandum Jurnal Pendidikan Dasar dan Pembelajaran, 9(2), 130-140.

Suardipa, I. P. (2020). Proses Scaffolding Pada Zone Of Proximal Development ( ZPD ) Dalam Pembelajaran. Widyacarya, 4(1), 79-92.

Sundari, F. S. (2020). Studi Komparasi Antara Model Pembelajaran Lesson Study dan Model Pembelajaran Direct Instruction Terhadap Keterampilan Menulis Teks Eksplanasi Ditinjau Dari Minat Belajar (Penelitian Eksperimen Pada Peserta Didik Kelas V Sd Negeri se-Kecamatan Laweyan Kota Surakarta Tahun Ajaran 2019/2020).

Sopandi, W. (2019). Sosialisasi dan Workshop Implementasi Model Pembelajaran RADEC Bagi Guru-Guru Pendidikan Dasar dan Menengah [Dissemination and Implementation Workshop of RADEC Learning Models for Primary and Secondary Education Teachers]. PEDAGOGIA: Jurnal Pendidikan, 8(1), 19. https://doi.org/10.21070/pedagogia.v8i 1.1853

Sugiyono. (2014). Metode Penelitian Kuantitatif, Kualitatif, dan $R \& D$.

Wahyu Sopandi, C. A., \& PPPPTKIPA, *1). Prodi Pendas SPS-UPIbandung; 2). (n.d.). MODEL PEMBELAJARAN RADEC Oleh: Wahyu Sopandi* 1), Chaerun Anwar 2) *1).

Yulistiani, D., \& Indihadi, D. Keterampilan Menulis Teks Eksplanasi dengan Menggunakan Media Gambar Berseri. PEDADIDAKTIKA: Jurnal Ilmiah Pendidikan Guru Sekolah Dasar, 7(3), 228-234. 